\title{
Editorial
}

\section{El Marketing} en la Agroindustria.

Dra. Manuela Camacho Gómez ${ }^{1}$

${ }^{1}$ Doctor en Educación Internacional. Coordinadora de Investigación y Posgado. División Académica de Ciencias Económico Administrativas de la Universidad Juárez Autónoma de Tabasco.
En las economías del mundo, las políticas públicas que impulsan el desarrollo, fortalecimiento o consolidación de los sectores, determina en gran medida la competitividad del país del que se trate. En este contexto, la agricultura es una de las principales generadoras de alimentos, ingresos y empleo, particularmente en territorios rurales. Todas las acciones estratégicas que fomenten este sector, sin duda, coadyuvarán a alcanzar la seguridad alimentaria con miras a un desarrollo integral sustentable.

La Agroindustria por su parte, enfoca sus esfuerzos hacia la transformación de los productos provenientes de la agricultura, ganadería, forestal y pesca. Este sector es el responsable de los procesos de producción, transformación y comercialización de productos primarios, añadiendo valor y dirigiendo sus esfuerzos hacia el mercado, mediante la integración vertical que articula el proceso, desde el campo hasta el consumidor o comprador final. El valor agregado en las agroindustrias se muestra de manera tangible a través de los empaques, embalajes, conservación, almacenaje, transporte y disponibilidad de productos procesados.

De acuerdo con una de las organizaciones que rigen el sector agroindustrial en México, la Secretaría de Agricultura, Ganadería, Desarrollo Rural, Pesca y Alimentación (SAGARPA), lo refieren como parte integrante de la industria manufacturera en la división de alimentos procesados y bebidas, la cual a su vez se conforma de 12 sub-industrias: carnes y lácteos, frutas y legumbres, molienda de trigo, molienda de nixtamal, beneficio y molienda de café, azúcar, aceites y grasas comestibles, alimentos para animales, otros productos alimenticios, bebidas alcohólicas, cerveza y malta, refrescos y aguas gaseosas, que a su vez se clasifican en 23 clases de actividades.

En los últimos 6 años, como parte de las políticas públicas del Estado mexicano, se ha buscado aumentar el grado de integración en las cadenas agroindustriales mediante la creación de asociaciones regionales y nacionales de productores agropecuarios, privilegiando la creación de las cadenas en determinados tipos de frutos, hortalizas y otros productos vegetales, cuya demanda puede ser estimulada a nivel nacional e internacional.

En lo que respecta al Producto Interno Bruto (PIB), según la SAGARPA, el valor agregado de la producción de alimentos aporta aproximadamente el $80 \%$ del PIB agroindustrial. En 2009, este PIB generó más de $\$ 436$ mil millones de pesos.

A nivel nacional, en los últimos 10 años, se ha incrementado la variedad de productos agroindustriales y la diversificación de mercados hacia los cuales 
pueden dirigirse; lo que ha generado la elaboración de estudios que den cuenta de las particularidades y necesidades de estos mercados potenciales. Esto implica que, las estrategias empresariales se deben diseñar acordes a las expectativas y a los estándares exigidos por los consumidores, quienes cada vez están más informados y por lo tanto más exigentes, particularmente en lo relativo a productos alimenticios. También se deben cumplir con las regulaciones propias del sector, teniendo presente las bases de sustentabilidad y medioambiental.

En esta tarea de fortalecer la competitividad del sector agroindustrial, una estrategia clave es el uso eficiente y eficaz del Marketing Agroindustrial, que apoye el diseño de los envases y empaques, la diversificación de productos, temporalidades, volúmenes, logística, distribución y fijación de políticas de precios acordes con las políticas del sector y la competitividad de los mercados meta.

Si bien, en la literatura del marketing, en la especialidad agroindustrial existen pocas referencias, la Food and Agriculture Organization (FAO), afirma que el Marketing Agroindustrial es la distinción entre industrias proveedoras de materias primas e industrias consumidoras de materias primas. Las primeras intervienen en la elaboración inicial de los productos agrícolas, como la molienda del trigo y el arroz, el curtido del cuero, el desmotado del algodón, el prensado del aceite, el aserrado de la madera y el enlatado de pescado. Las segundas se encargan de la fabricación de artículos a base de productos intermedios derivados de las materias agrícolas, como la fabricación de pan y galletas, de tejidos, de papel, de ropa y calzado o de manufacturas de caucho.

Bajo estas condiciones, se puede asumir que el marketing agroindustrial impulsa la transformación de bienes agrícolas en satisfactores, orientando sus esfuerzos hacia la generación de ventajas competitivas significativas para cada producto y mercado en particular, tomando en cuenta las tendencias a nivel mundial, siempre teniendo presente las buenas prácticas de manufactura, la preservación de los recursos y el cuidado del medio ambiente.

Las tendencias actuales en los mercados, evidencian la relevancia del valor agregado en productos agrícolas, cuya demanda se mantiene en los ámbitos nacional e internacional. En este sentido, las empresas agroindustriales y sus productos finales utilizan el Marketing Agroindustrial para difundirlos y hacerlos llegar al consumidor final, mediante estrategias apropiadas a los segmentos meta.

Analizando los cuatros elementos que conforman la mezcla del marketing (producto, precio, promoción y plaza), el principal elemento de esta área funcional de la empresa es el producto, ya que sus componentes o elementos permitirán la diferenciación necesaria para que los productos pasen de ser comodities a productos comerciales; es decir, productos primarios con valor agregado. 
En el marketing agrícola la variable precio es determinada por el mercado, por lo que los estudiosos de esta disciplina lo han asumido como un factor externo, ya que se asume que las empresas técnicamente no tienen posibilidad de fijar precios; sin embargo, los productos agroindustriales al ser transformados y al añadírles valor, se distinguen por características diferenciadoras que permiten establecer precios acordes con la demanda, la competencia y otras tendencias que el mercado les imponga.

En materia de promoción, la agroindustria posee varias alternativas para dar a conocer sus productos y servicios, tales como: el e-business, las páginas webs, las redes sociales, revistas especializadas y de especial atención, son la participación en ferias y exposiciones especializadas o multisectoriales, las cuales pueden ser a nivel nacional o internacional, tales como: la Winter Fancy Food Show que se realiza en San Francisco, California, USA; Fruit Logística en Berlín, Alemania; PRODEXPO en Moscú, Rusia relativa a exposición de cárnicos, bebidas alcohólicas y procesados; el BIOFACH Europa en Núremberg, Alemania, para la exposición de productos orgánicos; el CRFA en Toronto, Canadá, una exposición multisectorial y el International Boston Seafood Show, en Boston, Massachusetts, donde se exponen pescados y mariscos. Otras exposiciones multisectoriales son AGRITRADE en Guatemala y FOODEX en Tokio, Japón.

En México, se pueden localizar otras vertientes promocionales como el Foro Mundial de la Gastronomía Mexicana en Acapulco, Guerrero, Expo Mueble, foro para la exposición de fabricación de muebles y productos forestales en Guadalajara, Jalisco y el Festival del Chocolate en Villahermosa, Tabasco.

Respecto a la plaza, se asocia con la estimación de la demanda, la cual se refiere a los análisis cualitativos y cuantitativos de las ubicaciones geográficas donde se comercializan los productos tanto interna como externamente: potencial e índices de crecimiento, segmentación y nichos de mercado, canales de distribución y sistemas comerciales, factores socioculturales y macroeconómicos, frecuencias y tendencias de consumo y estimación de la demanda real.

De esta manera, se puede apreciar que la Agroindustria en México, tiene sus ventajas competitivas en la producción, pero no en el Marketing. El sector es altamente significativo en el país, especialmente por su participación en mercados externos caracterizados por la alta competencia con países que producen en ambientes de ventajas comparativas. Por lo tanto, el conocimiento del marketing agroindustrial es un área de oportunidad para la investigación y desarrollo de propuestas de esquemas teóricos que conduzcan a la producción de guías que favorezcan la implantación de estrategias de marketing apropiados al sector y a los contextos geográficos, culturales y económicos que correspondan.

El Marketing Agroindustrial coadyuva al desarrollo de los agronegocios, con un enfoque estratégico que orienta los esfuerzos desde una perspectiva de satisfacción de necesidades aunado al desarrollo de productos. Por esta razón, se asume que la tarea prioritaria del Marketing Agroindustrial es lograr que los productos derivados de éste sector logren la diferenciación en el mercado mediante el valor agregado, alcanzando estándares de calidad y consumo de los segmentos meta. 